\title{
ELES VÃO FICANDO MAIS PRÓXIMOS DO NORMAL... CONSIDERAÇÕES SOBRE NORMALIZAÇÃO NA ASSISTÊNCIA AO AUTISMO INFANTIL
}

\author{
Rosa Maria Monteiro López* \\ Cynthia Sarti**
}

\section{Apresentação}

Este artigo visa ressaltar formas implícitas ou explícitas de manifestação de uma tendência a seguir um padrão de normalidade nas práticas de assistência ao autismo infantil em diferentes instituições e abordagens, destacando suas implicações no que se refere às possibilidades que se abrem, ou fecham, à criança diagnosticada como "autista". Baseia-se em dados de uma pesquisa etnográfica desenvolvida em duas instituições paulistanas de assistência pública a crianças "autistas" - uma baseada em abordagem comportamental, a outra em abordagem psicanalítica -, cujo eixo de análise foram as construções

\footnotetext{
* Doutora em Saúde Coletiva pela Universidade Federal de São Paulo, mestre em Antropologia Social pela Universidade de São Paulo (USP) e bacharel em Ciências Sociais pela USP. E-mail: rosammlopez@yahoo.com.br.

** Professora titular na Universidade Federal de São Paulo (UNIFESP) onde trabalha desde 1994, doutora em Antropologia (1994) pela Universidade de São Paulo, livre-docente pelo Departamento de Medicina Preventiva da UNIFESP (2003). E-mail: csarti@uol.com.br.
} 
Eles Vão Ficando Mais Próximos do Normal...

conceituais sobre o autismo e as práticas de atendimento que lhes são correspondentes ${ }^{1}$. Considerando tanto o ponto de vista do saber médico/psicológico sobre o autismo, quanto o lado dos que recebem a assistência, e os desdobramentos dessa relação, buscou-se reunir elementos para apreender quem é a criança autista que resulta desses olhares diversos ou que se produz a partir desses pontos de vista a respeito da peculiaridade que apresenta sob a designação de autismo.

O autismo na infância constitui um fenômeno ao qual correspondem diversos modos de assistência, múltiplos como são os fatores associados à sua manifestação e as apresentações individuais do quadro. Dependendo da abordagem que se tome por referência, o autismo pode ser classificado como um dos Transtornos Globais (ou Invasivos) do Desenvolvimento - como figura nos manuais diagnósticos de maior difusão e influência no campo da psiquiatria moderna ocidental (DSM-IV ${ }^{2}$ e CID-10 ${ }^{3}$. Em outra vertente, pode ser incluído entre as chamadas psicoses infantis ou precoces, como consta de manuais de psiquiatria infantil como o de Ajuriaguerra (1977) e da classificação francesa de distúrbios mentais da infância e da adolescência (CFTMEA, 2000).

Esses polos de divergência classificatória estão longe de se equilibrarem, pelo menos entre as referências que compõem o quadro de entendimento e tratamento da peculiaridade desse transtorno no mundo ocidental, sendo marcante a hegemonia da classificação do autismo e suas variações como transtornos

\footnotetext{
${ }^{1}$ Trata-se de tese de doutorado (López, 2012), desenvolvida no Programa de Pós-Graduação em Saúde Coletiva da UNIFESP, sob orientação de Cynthia Sarti, com bolsa FAPESP.

${ }^{2}$ ASSOCIAÇÃO PSIQUIÁTRICA AMERICANA. Manual Diagnóstico e Estatístico de Transtornos Mentais (DSM-IV). Porto Alegre: Artes Médicas, 1995.

${ }^{3}$ ORGANIZAÇÃO MUNDIAL DE SAÚDE. Classificação de transtornos mentais e de comportamento: CID-10. Porto Alegre: Artes Médicas, 1993.
} 
globais do desenvolvimento - deste ponto de vista, disfunções orgânicas. Isso acontece a ponto de praticamente inexistirem, em alguns países e regiões, menções ou espaço para a atuação de modelos alternativos aos que se baseiam nessa referência (como as leituras psicodinâmicas acima citadas), seguindo a tendência geral no campo da saúde mental de predomínio da classificação nosológica baseada no modelo psiquiátrico norte-americano que, segundo Russo e Venâncio (2006), operou uma "virada fisicalista", identificada a partir da década de 1980 nos protocolos que orientam a prática psiquiátrica desde o DSM-III, em contraposição à orientação anterior (DSM-II) na qual se observava a hegemonia da psicanálise na interpretação das perturbações mentais. Assim, "o velho dualismo mente/corpo tem sido deixado de lado em favor de um monismo fisicalista radical" (Russo et. al., 2004, p. 39). No Brasil, mesmo confirmando-se essa hegemonia, é possível encontrar modelos de assistência ao autismo orientados pela psicanálise.

O termo autismo, aqui empregado em sentido amplo, abrange, assim, o que a psiquiatria moderna define como distúrbios do desenvolvimento situados no espectro autista - desde o autismo "clássico", muitas vezes associado a retardo mental, que gera "autistas de baixo funcionamento", até a "síndrome de Asperger", forma branda de autismo por vezes associada a "ilhas de habilidades" acima das pessoas comuns -, e também interpretações psicodinâmicas de quadros assemelhados, que diversos autores denominam preferencialmente como "psicoses infantis", grupo de transtornos mais abrangentes do qual o autismo faria parte.

O fato de se optar pelo termo autismo como unificador da problemática em questão não representa a mesma adesão à lógica de classificação dos manuais diagnósticos DSM-IV e CID-10. Embora para a orientação psicanalítica predominante na instituição aqui denominada terapêutica o termo autismo não dê conta de todas as manifestações observadas nas crianças assistidas em seu programa de atendimento, ele tampouco é descartado. 
Eles Vão Ficando Mais Próximos do Normal...

É considerado parte do grupo das psicoses infantis, equivalente ao que se denomina "psicose precoce" ${ }^{4}$. Já para a abordagem comportamental, o termo psicose não se coloca, nem é associado aos "transtornos globais do desenvolvimento" nas versões mais recentes dos manuais diagnósticos citados.

\section{As instituições e suas especificidades}

Por questões éticas, optou-se por não identificar diretamente as instituições aqui enfocadas. Com base nas características distintivas das mesmas, escolheu-se destacar uma especificação diferencial e nomear uma delas como instituição educacional e a outra como instituição terapêutica, identificação pela qual serão consideradas neste artigo. Em toda a pesquisa, os nomes de profissionais, crianças e familiares citados são sempre fictícios.

Fundada por um grupo de pais de crianças autistas, na cidade de São Paulo, na década de 1980, a instituição educacional surgiu a partir da mobilização e do esforço conjunto desses pais em busca de atendimento adequado para seus filhos, num momento em que as informações e recursos para lidar com o autismo eram bastante escassos no Brasil. Como entidade sem fins lucrativos, a instituição sempre precisou contar com doações, apoio de empresas e de órgãos governamentais para desenvolver, manter e expandir suas atividades. Atualmente, a ampla maioria dos atendimentos prestados é gratuita.

\footnotetext{
${ }^{4}$ Cabe ressaltar que o termo autismo é usado habitualmente em psicanálise, não exatamente com a mesma abrangência e características com que essa classificação está especificada nos manuais diagnósticos de maior difusão no campo da psiquiatria moderna ocidental. Apenas como demonstração da diversidade interna ao próprio campo psicanalítico para o emprego do termo, pode-se citar que, para a linha de orientação lacaniana, autismo e psicose não participam de uma mesma categoria psicopatológica, sendo consideradas manifestações distintas.
} 
Somando-se os atendidos pela instituição educacional nas três regiões da cidade em que está presente, há pouco mais de 200 assistidos, entre crianças, jovens e adultos com diversos "graus" de autismo. O número de funcionários envolvidos nessa tarefa fica um pouco abaixo de 200, quadro reforçado por cerca de 50 estagiários (dados de 2011). Entre os profissionais que lidam mais diretamente com os autistas, a maior parte é de pedagogos. Atuam também nessa interface os formados em psicologia, educação física, fisioterapia, fonoaudiologia, psiquiatria e terapia ocupacional, além de empregados que exercem outras funções de nível médio e demais profissionais da área administrativa.

A orientação do trabalho na instituição educacional tem como base a definição de que condições no espectro do autismo são transtornos do desenvolvimento causados por anormalidades físicas em parte do cérebro (Wing, 1996). Consonante com essa premissa, a assistência oferecida segue a linha comportamental e enfatiza a "educação especial diária" (quatro horas de atividades e permanência na instituição, de segunda a sexta-feira) que tem o TEACCH (Treatment and Education of Austistic and related Communication Handicaped Children) como um dos pilares do seu modelo de atendimento. Trata-se de um programa para tratamento e educação de crianças autistas e portadoras de problemas de comunicação correlatos fundado nos anos 1970 por Eric Schopler, pesquisador do Departamento de Psiquiatria da Faculdade de Medicina da Universidade da Carolina do Norte, em Chapell Hill, Estados Unidos.

Nessa instituição, a "educação especial diária" é exposta como o meio que visa ajudar o portador de autismo a chegar à idade adulta com o máximo de "autonomia" 5 possível. Isso significa, nessa perspectiva, ajudá-lo a compreender o mundo que o cerca através

${ }^{5}$ Autonomia é o termo que a instituição utiliza para caracterizar seus objetivos. O significado da palavra nesse contexto, no entanto, limita-se à referência ao desempenho de atividades da vida diária e a trocas comunicativas básicas para este fim. 
Eles Vão Ficando Mais Próximos do Normal...

da aquisição de habilidades de comunicação que permitam relacionar-se com outras pessoas. O ensino estruturado é o meio facilitador tido como mais eficiente para o desenvolvimento da comunicação e da "independência" dos alunos com autismo. Esse modelo de ensino é visto como o apoio para que o aluno consiga superar os déficits relacionados ao autismo e ser bem sucedido em sua experiência de aprendizado.

Já a instituição aqui chamada de terapêutica constitui-se como uma unidade de atendimento ambulatorial e de desenvolvimento de atividades de ensino e pesquisa vinculada ao Departamento de Psiquiatria de uma universidade pública da capital paulista. A assistência nesse serviço é gratuita e abrange diversos problemas clínicos na área de saúde mental para a infância e adolescência, estando o autismo - ou as psicoses da infância ${ }^{7}$, termo mais abrangente ali preferencialmente adotado - entre os quadros atendidos.

Trata-se de um espaço físico dedicado especialmente a essa faixa etária, assim idealizado e viabilizado há cerca de dez anos, contando com o apoio de um convênio com a Secretaria Estadual da Saúde. A história desse tipo específico de atividade dentro da universidade, porém, é bem mais longa, ultrapassando duas décadas de trabalho que tem até hoje a colaboração de profissionais que iniciaram esse serviço no passado.

A equipe de trabalho da instituição é composta por aproximadamente 30 pessoas e seu caráter é multiprofissional, incluindo psiquiatras, pediatra, psicólogos, assistentes sociais, terapeuta ocupacional, fonoaudióloga, psicopedagoga, enfermeira, musicoterapeuta e demais auxiliares e pessoal da área administrativa. Numericamente, os psicólogos constituem a formação profissional de maior representatividade no conjunto.

\footnotetext{
${ }^{6}$ Independência igualmente pensada, aqui, em termos do desempenho de tarefas cotidianas, sem qualquer referência à subjetividade.

${ }^{7}$ Mais recentemente, a instituição tem caracterizado o trabalho com esse segmento como "atendimento a crianças com transtornos globais do desenvolvimento", como consta de site institucional.
} 
Alguns segmentos da população assistida contam com programas específicos de atendimento. Esse é o caso das crianças com quadros clínicos indicativos de psicoses, incluindo o autismo. Um grupo de profissionais da equipe da instituição, com formações acadêmicas diversas, dedica-se a desenvolver e pôr em prática estratégias de trabalho com essas crianças e seus familiares ${ }^{8}$, investindo na possibilidade de criar relações de troca com as crianças assistidas.

Somando-se os atendimentos realizados nos programas intensivos e os de ambulatório, estima-se que o total ultrapasse com folga os 1000 atendimentos mensais (dados de 2011). No caso dos clientes ${ }^{9}$ do programa de atendimento às psicoses da infância, existem dois grupos de atendidos (cada um composto por cerca de 40 crianças e seus familiares) e duas equipes de profissionais dedicadas a esse trabalho, de acordo com o período de atividades (manhã ou tarde).

Da perspectiva da instituição terapêutica, o autismo ou as psicoses da infância são concebidos como fenômenos cuja etiologia não se restringe a questões orgânicas, considerando-se, inclusive, que tal "base biológica" por vezes nem pode ser constatada, ou parece longe de ser preponderante. Consta de material informativo produzido por essa instituição a afirmação de que, no modelo de atendimento ali praticado, não são dados à psicose infantil e ao autismo o estatuto de doença instalada na biologia do corpo, mas o de uma perturbação no processo de formação das estruturas mentais primitivas que dependem basicamente de uma relação humana adequada para se desenvolverem. A proposta de trabalho, informada pela teoria e prática psicanalíticas, prioriza a questão relacional e, assim, incorpora estratégias terapêuticas que

\footnotetext{
${ }^{8}$ Diferentemente da instituição educacional, a instituição terapêutica inclui os familiares entre os atendidos.

${ }^{9}$ Esse é um termo de uso estimulado internamente, devido à consideração de que, pelo menos em tese, o termo "paciente" implica subordinação.
} 
Eles Vão Ficando Mais Próximos do Normal...

envolvem necessariamente a participação dos familiares das crianças atendidas no programa.

\section{Graus de normalidade}

Às significativas distinções conceituais que informam o trabalho de cada uma das instituições pesquisadas correspondem práticas de assistência a crianças e familiares igualmente diversas. Em relação à atuação dos dois serviços, pode-se notar uma referência à "normalidade" que incide muito mais explicitamente na instituição educacional, sendo frequente nesse contexto a comparação das crianças portadoras de autismo com crianças/adolescentes ditos "normais", situando os primeiros em termos de "faltas", "déficits", inabilidades.

Em palestra feita durante um treinamento para candidatos a estágio na instituição educacional, uma profissional ligada à coordenação - que tem um filho portador de autismo definido por ela como muito comprometido cognitivamente - comenta uma atividade que vem sendo desenvolvida na instituição para ensinar os autistas a brincar. Na descrição das etapas que fariam os atendidos evoluírem da brincadeira até o jogo, tudo parece se dar a partir da imitação (algo difícil de aprender para as pessoas com autismo, na visão desses profissionais) e da exaustiva repetição. Está implícita a ideia de que a criatividade é outra "ausência" típica do autismo. Ela dá vários exemplos de montagem de blocos, depois mosaicos, sugere até que se podem organizar pequenos diálogos, que são decorados e vão sendo encenados, acabando por ser assimilados pela repetição, o que ela ressalta não se tratar exatamente de compreensão. Para a expositora, com o desenvolvimento de atividades como essas, as pessoas com autismo geralmente terão alguns ganhos, e completa: É importante saber que eles vão continuar sendo chatos, esquisitos... Mas a esquisitice passa mais despercebida, vão ficando mais próximos do normal...

Levar os atendidos a parecerem mais normais ou a terem comportamentos mais adequados são objetivos consonantes com a "melhor adequação possível à nossa sociedade", descrita como 
meta do programa TEACCH. Ao mesmo tempo em que se atribui ao autismo uma "cultura própria", o que poderia conduzir a um reconhecimento de "identidade social diferenciada", fala-se em transtorno de desenvolvimento caracterizado por dificuldades e anormalidades em várias áreas: habilidades de comunicação, relacionamento social, funcionamento cognitivo, processamento sensorial e comportamento. Todos os esforços são feitos, assim, no sentido de "amenizar" as características autísticas, torná-las menos perceptíveis (aos outros), tendo como referência as práticas de aprendizagem, o desenvolvimento e o comportamento tidos como normais na sociedade onde se inserem as crianças autistas. A afirmação de Mesibov e Shea [s.d.] de que "pela razão dos problemas de base orgânica determinantes do autismo não serem reversíveis, não tomamos a 'normalidade' como meta de nossos esforços terapêuticos e educacionais", soa como mera declaração de princípios, diante de práticas que indicam claramente um padrão de normalidade a ser seguido. Parecer "normal" torna-se a alternativa vislumbrada para evitar o incômodo causado pela diferença evidenciada pela peculiaridade da criança autista, esquisita.

Em O Normal e o Patológico, originalmente escrito em 1943 como tese de doutorado, Canguilhem (2002) analisa as implicações e valores envolvidos nas classificações que dão título à obra, o que ajuda a ampliar os questionamentos sobre os maniqueísmos e os problemáticos enquadramentos diagnósticos médicos, ainda mais duvidosos quando se tratam de perturbações mentais com etiologias não conclusivamente definidas, como é o caso do autismo. Em 1966, mais de vinte anos depois da publicação do trabalho original e influenciado pela obra de Michel Foucault para quem a norma é produzida pela ordem social, como destaca Roudinesco (2007) -, Canguilhem define o ato de normalizar

[...] é impor uma exigência a uma existência, a um dado, cuja variedade e disparidade se apresentam, em relação à exigência, como um indeterminado hostil, mais ainda do que estranho. [...] Uma norma 
$|86|$

Eles Vão Ficando Mais Próximos do Normal...

só é a possibilidade de uma referência quando foi instituída ou escolhida como expressão de uma preferência e como instrumento de uma vontade de substituir um estado de coisas insatisfatório por um estado de coisas satisfatório. Assim, qualquer preferência de uma ordem possível é acompanhada - geralmente de maneira implícita - pela aversão à ordem inversa possível. O oposto do preferível, em determinado campo de avaliação, não é o indiferente e sim aquilo que é repelente, ou, mais exatamente, repelido, detestável. [...] Sob qualquer forma implícita ou explícita que seja, as normas comparam o real a valores, exprimem discriminações de qualidades de acordo com a oposição polar de um positivo e de um negativo (Canguilhem, 2002, p. 211-212).

Nas reflexões de Canguilhem sobre a norma e seu caráter relacional, presentes na obra acima citada, aparece a comunhão de pontos de vista com Foucault no que se refere à crítica à sociedade ocidental moderna. Conforme destaca Portocarrero (2009, p. 212-213), o ponto de partida de Foucault ao estudar o caráter da sanção normalizadora da disciplina é a afirmação de Canguilhem de que o termo normal designa, a partir do século XIX, o protótipo escolar e o estado de saúde orgânica. A utilização do termo é correlata da reforma pedagógica e da teoria científica médica, estreitamente ligadas à reforma das práticas pedagógica, médica e hospitalar. Há uma exigência de racionalização expressa nessas reformas que também aparece na política e na economia, alcançando o que é chamado mais tarde de normalização.

Em Vigiar e Punir, Foucault (1987) analisa a paulatina metamorfose, entre finais do século XVIII e início do século XIX, dos métodos de punição baseados em suplícios ostensivos para uma prática punitiva que “[...] procurará pôr o máximo de distância possível entre a pesquisa 'serena' da verdade e a violência que não se pode eliminar inteiramente da punição” (p. 48).

A disciplina se instaura como nova anatomia política. Esta se difunde em uma multiplicidade de processos em funcionamento, 
por exemplo, nas escolas, no espaço hospitalar, na organização militar. Segundo Foucault, o sucesso do poder disciplinar se deve sem dúvida ao uso de instrumentos simples: o olhar hierárquico, a sanção normalizadora e sua combinação num procedimento específico, o do exame (Foucault, 1987, p. 143).

Ter o diagnóstico de autismo atestado por um médico, geralmente psiquiatra ou neurologista, é condição fundamental para que a criança possa ser assistida na instituição educacional, o que se efetiva a partir do encaminhamento da criança via Secretaria de Educação e da existência da vaga para que ela passe a frequentar diariamente as atividades no período da manhã ou da tarde.

Na unidade da instituição que atende exclusivamente crianças até 12 anos, são cerca de 25 a 30 crianças por período, dispostas em cinco salas de acordo com a idade e grau de "comprometimento cognitivo" que apresentam. Além da situação de avaliação médica vivenciada para classificar e atestar a "diferença", ou a "atipicidade" da criança que será assistida na instituição educacional, ela será submetida ao chegar a outro procedimento típico do exame de que trata Foucault. Antes que integre uma das salas e comece a realizar as atividades propostas, cada criança é avaliada individualmente a partir da aplicação de um instrumento chamado Perfil Psicoeducacional Revisado (PEP-R).

Elaborado por uma equipe de clínicos do Departamento de Psiquiatria da Universidade da Carolina do Norte (EUA) que inclui os criadores do método TEACCH (Tratamento e educação de crianças autistas e portadoras de problemas de comunicação correlatos), o PEP-R é utilizado para identificar habilidades e dificuldades de aprendizado de crianças com "transtornos do espectro autista". Os dados obtidos embasam a composição do planejamento psicoeducacional individual, segundo os princípios do modelo TEACCH. Partindo de uma abordagem 
desenvolvimentista ${ }^{10}$, o instrumento apresenta um inventário de comportamentos e habilidades para identificar padrões de aprendizagem. De acordo com o que descreve apostila fornecida em um curso desenvolvido pela instituição educacional, a maioria dos itens de avaliação do PEP-R não depende da linguagem verbal e tem aplicação flexível, permitindo ajustes aos problemas de comportamento da criança.

Constam também desse material distribuído em cursos e de autoria imprecisa comentários sobre as razões pelas quais a perspectiva desenvolvimentista é enfatizada na avaliação de crianças autistas proporcionada pelo PEP-R. Diz-se que, em primeiro lugar, a perspectiva desenvolvimentista "[...] serve como um 'lembrete' de que as habilidades adaptativas das crianças e as manifestações de suas desvantagens são formadas, ao menos parcialmente, por sua idade e nível de desenvolvimento". O texto explica em seguida que tais considerações não significam afirmar que os comportamentos de crianças com transtorno de desenvolvimento sejam como os das crianças normais mais novas.

Pelo contrário, os padrões de aprendizagem irregulares característicos destas crianças as tornam muito diferentes umas das outras, e também torna diferente das experiências que a maioria dos adultos tem com as crianças normais. Entretanto, uma forma sensata e humana de alcançar a compreensão especial necessária destas crianças é perceber suas similaridades e necessidades em comum com crianças normais mais novas. Esta comparação é o

\footnotetext{
${ }^{10}$ Segundo Lampreia (2007, p.106), a característica central da abordagem desenvolvimentista do autismo seria "[...] procurar compreender as peculiaridades e desvios do desenvolvimento da criança portadora de autismo a partir, ou à luz, do desenvolvimento típico. Essas peculiaridades envolvem, primordialmente, uma falha no desenvolvimento dos precursores da linguagem, isto é, da comunicação não verbal".
} 
componente mais útil para entender e ensinar estas crianças $^{11}$ (grifos nossos).

A avaliação compreende duas escalas, uma relativa ao Desenvolvimento e outra ao Comportamento. Na escala de Desenvolvimento, as áreas avaliadas são Imitação, Percepção, Integração Olho-mão, Coordenação Motora Fina, Coordenação Motora Grossa, Desempenho Cognitivo e Cognição Verbal. Já a escala de Comportamento avalia as áreas de Relacionamento e Afeto, Brincar e Interesse por Materiais, Respostas Sensoriais e Linguagem.

Cada área tem suas provas específicas, totalizando 131 itens. Há uma padronização dos materiais de teste, que incluem massas de modelar, discos e blocos coloridos, instrumentos sonoros, livros de imagens, cartões com números, quebra-cabeças, entre vários outros objetos. A apresentação de cada item pode dar-se de forma verbal, gestual ou até mesmo por demonstração feita pelo examinador. $\mathrm{O}$ examinador observa, avalia e anota a resposta da criança durante o teste. Para cada resposta, há três possibilidades de registro: passou (a criança realizou a tarefa com sucesso), reprovado (a criança não conseguiu realizar a tarefa) e emergindo (a criança conseguiu realizar a tarefa com a ajuda do examinador) (Leon, 2002, p. 37).

A escala de Desenvolvimento visa avaliar, segundo a apostila fornecida pela instituição educacional, "como a criança está funcionando em relação a uma criança normal". Já a escala de Comportamento indica "a gravidade das dificuldades de comportamento da criança, além de fornecer informações do grau de comportamento inadequado e disfuncional da criança, indicando as áreas específicas nas quais esses comportamentos são manifestados".

Em material produzido pela Secretaria de Educação Especial do Ministério da Educação brasileiro que reúne informações

\footnotetext{
11 "Uma abordagem desenvolvimentista aplicada à avaliação". Fotocópia distribuída em treinamento.
} 
e orientações relativas à inclusão de crianças com autismo para professores da rede de ensino regular, afirma-se que a aplicação do PEP-R dá como resultado a idade cronológica correspondente ao nível de desenvolvimento apresentado pelo aluno com autismo (Monte; Santos, 2004, p. 25). Faz-se também uma analogia entre o coeficiente de desenvolvimento por meio do referido teste e o número obtido por meio dos testes de inteligência, apontando similaridades entre os dois.

Mais uma vez, tem-se a comparação clara e intencional dos autistas assistidos na instituição educacional com as crianças ditas "normais", em termos de habilidades e de comportamentos que se presume constituírem referências de adequação e capacidade em cada faixa etária. O que não corresponde a esse padrão ajudará a caracterizar o "grau de comprometimento" da criança em questão, levando a definir o autismo que ela apresenta com o uso de termos como "leve", "moderado" ou "severo". Conforme considera Foucault em relação ao instrumento disciplinar do exame, a escola torna-se uma espécie de aparelho de exame ininterrupto, que acompanha em todo o seu comprimento a operação de ensino.

O exame não se contenta em sancionar o aprendizado; é um de seus fatores permanentes: sustenta-o segundo um ritual de poder constantemente renovado. $\mathrm{O}$ exame permite ao mestre, ao mesmo tempo em que transmite seu saber, levantar um campo de conhecimentos sobre seus alunos (Foucault, 1987, p. 153).

Os procedimentos de exame são acompanhados imediatamente de um sistema de registro intenso e de acumulação documentária. Fazendo o sujeito existir a partir de um campo documental, tem-se como resultado um arquivo inteiro com detalhes e minúcias que se constitui "ao nível dos corpos e dos dias". O exame que coloca os indivíduos num campo de vigilância, aponta Foucault (1987, p. 157), situa-os igualmente numa rede 
de anotações escritas; compromete-os em toda uma quantidade de documentos que os captam e os fixam.

No dia-a-dia das atividades na instituição educacional, é possível observar que, como enfatizado em palestra de uma das coordenadoras, a técnica básica de ensino ali utilizada é a repetição. Acompanhando-se o programado para cada uma das crianças durante seus períodos de trabalho em sala de aula, nota-se uma série de tarefas com execução registrada em pastas individuais nas quais os professores anotam minuciosamente cada habilidade treinada e a forma de sua execução no dia-a-dia. $\mathrm{O}$ registro parece merecer mais atenção do que a execução da tarefa pela criança.

Na observação do trabalho acontecendo em sala, das crianças executando as tarefas que parecem já ter feito muitas vezes antes (a única limitação recomendada para a repetição de tarefas é que não se faça exatamente a mesma mais de uma vez no mesmo dia), torna-se bastante difícil distinguir entre o que, mesmo nos termos desse método, foi "aprendido" e o que foi "decorado", ou "automatizado", já que existe a suposição prévia de que não será assimilada a tarefa como sentido. A criança autista, aqui, é "deficitária" por definição e o atendimento a ela dispensado visa aproximá-la do referencial positivo e nunca alcançado a partir do qual ela é julgada deficitária, no processo que Canguilhem chamou de normalização.

\section{A criança autista: entre o cérebro e os afetos}

Definir quem é, ou como é a criança autista vai depender muito de quem a olha e de como ela é vista. As controvérsias começam pela própria qualificação dos termos que a definem, mesmo entre os que aceitam chamar de autismo o fenômeno em questão. Mônica, que atuou como psiquiatra na instituição educacional, por exemplo, chama as crianças que atende de "meninos com autismo", ou com transtorno global do desenvolvimento, ou simplesmente "meninos", como um modo 
Eles Vão Ficando Mais Próximos do Normal...

tido como aparentemente menos estigmatizante de se referir a essas crianças. $\mathrm{O}$ caminho para se compreender sua evitação da palavra "autista", no entanto, pode ser outro.

Um movimento que vem ganhando visibilidade em anos recentes, chamado "movimento da neurodiversidade", traz elementos para se compreender a preferência das associações de pais de autistas e profissionais pelo termo "pessoas com autismo" em detrimento da palavra "autista". Em clara oposição aos grupos de pais citados, o movimento da neurodiversidade - organizado basicamente por autistas de "alto funcionamento" - considera que o autismo não é uma doença a ser tratada e nem deve ser colocada na perspectiva de uma possível cura. Trata-se antes de uma diferença humana que deve ser respeitada como outras diferenças, tais como as sexuais, raciais, entre outras (Ortega, 2009).

Como destaca Ortega (2008), é o estatuto ontológico do autismo que está sendo disputado na oposição referida: doença para uns, exemplo de diversidade do cérebro humano para outros. Daí a distinção entre ser autista e ter autismo. Para os pais organizados em associações que consideram o autismo um transtorno e buscam a implantação de terapias cognitivas e comportamentais, com vistas a uma possível cura (que não está inteiramente fora do horizonte), tal transtorno é visto como uma doença com uma etiologia orgânica, principalmente cerebral e/ou genética. Nesse sentido, suas crianças não são autistas, elas têm autismo, o grupo nega-se a reconhecer no autismo uma questão de identidade. Já para os ativistas autistas integrados ao movimento da neurodiversidade, o transtorno remete a uma questão identitária. Autismo não é uma coisa (uma doença) que se tem, mas algo que se é (Ortega, 2008).

Do ponto de vista dos pais de crianças com autismo, é relevante a posição que faz lembrar aos ativistas da neurodiversidade - praticamente todos caracterizados como autistas de alto funcionamento ou portadores da Síndrome de Asperger que autistas com amplos recursos cognitivos, como esses, não correspondem à realidade de todo o espectro autista, nem à maior 
parte dele, e que é muito difícil para os de "baixo funcionamento" adquirir habilidades e "autonomia" sem ajuda técnica especializada. Já o lado dos autistas ativistas tem argumentos fundamentados para criticar os modelos tradicionais de educação especial oferecidos para o tratamento do autismo, sempre pensados em termos de deficiências e aproximação à normalidade, sem um verdadeiro respeito pela diferença de cada criança.

O trabalho de Ortega $(2008,2009)$, que analisa a relação entre grupos pró-cura e anti-cura do autismo, levanta a intrigante questão de que foi o deslocamento do paradigma psicanalítico para o cerebral que possibilitou a organização desses dois grupos antagônicos, mostrando uma polaridade distinta daquela que informou o desenho desta pesquisa que analisou a instituição educacional, de base comportamental e a instituição terapêutica, de base psicanalítica. Para o movimento de pais de autistas, localizar o autismo no cérebro desculpabiliza-os pelo transtorno (principal acusação feita à abordagem da psicanálise) ${ }^{12}$, apontando para uma causalidade concreta e objetiva.

Em ambos os casos, apesar das divergências, observa-se um processo de descrição da individualidade e da subjetividade em termos corporais, com o cérebro ocupando um lugar privilegiado, o que implica uma dessubjetivação. No caso dos

${ }^{12}$ Como parte do processo de transformação pela qual passou o campo psiquiátrico nas últimas décadas do século $X X$ - período em que uma visão que poderia ser chamada de "psicossocial" dos transtornos mentais cedeu lugar a uma visão estritamente biológica (Russo et al., 2004) difundiram-se críticas às teorias psicanalíticas devido ao fato de que elas supostamente culpabilizariam os pais pelo autismo dos filhos. À sugestão de Kanner (1997) - primeiro psiquiatra a descrever o "distúrbio autístico", em 1943 - de que a condição das crianças que ele estudou era também devida ao fato de serem criadas por pais frios, desapegados, sem humor e rígidos, o que alguns chamaram de "teoria das causas emocionais", foram atribuídos "efeitos devastadores" para as famílias de autistas, segundo Wing (1996), efeito que foi "combatido" nesse momento posterior de mudança de concepções predominantes em relação ao autismo e de criação das primeiras associações de pais de autistas em diversos países. 
Eles Vão Ficando Mais Próximos do Normal...

movimentos da neurodiversidade, esse "cerebralismo" constitui uma marca identitária, uma identidade naturalizada em bases biológicas, não pelo autismo ser uma doença mental, mas precisamente porque é uma "conexão atípica" do cérebro, sempre tomando o cérebro como referência (Ortega, 2008). Estranho paradoxo o de se afirmar, no século XXI, identidades a partir de características cerebrais, quando se pensa na luta dos movimentos libertários, de base identitária, que se originaram na segunda metade do século XX precisamente como forma de demarcar a construção social de identidades, rompendo com a naturalização da condição das mulheres, dos negros, dos homossexuais, que os fixava a um destino a partir de atributos de base biológica que fundamentavam a discriminação desses grupos sociais...

Em relação às crianças assistidas nas duas instituições pesquisadas, pôde-se constatar que existe uma importante distinção entre as concepções de pessoa que informam as intervenções em cada uma delas. Da parte da instituição educacional, uma palavra que possivelmente sintetizaria os objetivos da assistência é funcionalidade. É o que se busca no trabalho desenvolvido no dia a dia com as crianças, que "alcancem ganhos" no sentido de comunicar-se mais funcionalmente, brincar mais funcionalmente, interagir socialmente com um mínimo de funcionalidade e o máximo de controle em relação a "comportamentos inadequados". A criança com autismo é, nesse contexto, uma pessoa que se busca adaptar ao mundo social, contornando limitações e "educando" pela dimensão prática do adestramento e da submissão para que pareça "mais próximo do normal". A singularidade, a subjetividade e o desejo dos "alunos" não estão entre os focos de interesse e de atuação previstos nessa abordagem.

A criança autista da instituição terapêutica é um ser considerado em sua singularidade, alguém que, por várias razões, não pôde ainda constituir-se como sujeito, ou cuja subjetividade encontra-se comprometida em seu desenvolvimento. $\mathrm{O}$ objetivo principal da assistência empreendida é propiciar as condições para que esse sujeito se constitua ou seja resgatado, permitindo-se assim 
(idealmente) a possibilidade de expressão de sua particularidade e de seu desejo. Deste ponto de vista institucional, a assistência só pode se efetivar a partir de mediações, relações, trocas afetivas que sejam favoráveis à criança. É o que se busca a partir da tentativa de contato com ela própria e do trabalho com familiares.

Mesmo quando se tenta não enxergar nessas crianças e famílias peculiares a materialização de uma "doença", é preciso estar sempre atento aos desdobramentos que classificações diagnósticas como a do autismo costumam gerar. Cavalcanti e Rocha (2007) chamam a atenção para o "efeito iatrogênico" - ação danosa adversa - que o diagnóstico "autismo infantil precoce" contém, pelo impacto sobre aqueles que estão ao redor da criança:

Diante desse diagnóstico não é raro que pais e familiares retirem seus cuidados das crianças e passem a tratá-las como 'doença' ou - o que é pior pelo que imaginam que é essa “doença' (p. 64).

Os profissionais envolvidos no atendimento a essas crianças também muitas vezes participam desse mesmo efeito:

Se estamos fadados, pelo constrangimento de nossas narrativas, a ver e descrever essas crianças através de suas deficiências, ficamos cegos e surdos para suas capacidades, assim como cegos e surdos ficam seus próprios pais. (Cavalcanti; Rocha, 2007, p. 64).

Qualquer caminho que se tome para buscar auxiliar crianças que tenham a peculiaridade de apresentar amplas dificuldades em seu desenvolvimento tem implicações, limites e consequências. A cristalização de atributos que as classificações diagnósticas geralmente propiciam é temerária, especialmente na infância. Concluímos com a sugestão de Rabello (2010) de que se considere a "inespecificidade" peculiar à criança como um dado positivo.

A criança reside no campo da imprevisibilidade, esse é o seu grande trunfo, e devemos defendê-lo. Assim, seja qual for o 
déficit identificado, este deve convidar à compreensão da lógica psíquica que o define, e para tal, ao necessário resgate clínico minucioso da organização de seus aspectos estruturais, ambientais e subjetivos, construindo, para além da face impessoal do déficit, a peculiaridade discreta do sofrimento que o determina e também dos caminhos de sua resolução, mesmo que parcial ou paulatina ${ }^{13}$.

\section{Bibliografia}

AJURIAGUERRA, J. "Las psicosis infantiles (Capítulo XX)”.

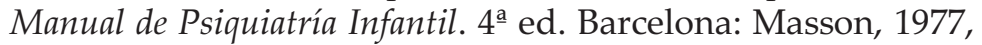
p. 673-731.

ASSOCIAÇÃO PSIQUIÁTRICA AMERICANA. Manual Diagnóstico e Estatístico de Transtornos Mentais (DSM-IV). Porto Alegre: Artes Médicas, 1995.

CANGUILHEM, G. O Normal e o Patológico. 5aa ed. Rio de Janeiro: Forense Universitária, 2002.

CAVALCANTI, A. E.; ROCHA, P. S. Autismo: construções e desconstruções. São Paulo: Casa do Psicólogo, 2007.

CFTMEA 2000: Nouvelle version de la Classification Française des Troubles Mentaux de l'Enfant et de l'Adolescent. Disponível em: $<$ http://psydoc-fr.broca.inserm.fr/ bibliothq/default.html> Acesso em: 03 fev. 2013.

FOUCAULT, M. Vigiar e Punir: nascimento da prisão [1975]. $26^{a}$ ed. Petrópolis: Vozes, 2002.

KANNER, L. "Os distúrbios autísticos do contato afetivo" [1943]. In: ROCHA, P. S. (org.) Autismos. São Paulo: Editora Escuta, 1997.

13 Transcrição de gravação da apresentação oral (Rabello, 2010). 
LAMPREIA, C. "A perspectiva desenvolvimentista para a intervenção precoce no autismo". Estudos de Psicologia, v. 24, n. 1, p. 105-114, 2007.

LEON, V. C. Estudo das propriedades psicométricas do Perfil Psicoeducacional PEP-R: elaboração da versão brasileira. 2002. 122 f. Dissertação (Mestrado em Psicologia) - Universidade Federal do Rio Grande do Sul, Porto Alegre.

LÓPEZ, R. M. M. Olhares que constroem: a criança autista das teorias, das intervenções e das famílias. 2012. 199f. Tese (Doutorado em Saúde Coletiva) - Universidade Federal de São Paulo, São Paulo.

MESIBOV, G.; SHEA, V. The culture of autism: from theoretical understanding to educational practice. Disponivel em: <http:// www.autismuk.com/?page_id=104>. Acesso em: 02 fev. 2013.

MONTE, F. R. F.; SANTOS, I. B. (Coords.). Saberes e práticas de inclusão: dificuldades acentuadas de aprendizagem. Autismo. Brasília: MEC, SEESP, 2004.

ORGANIZAÇÃO MUNDIAL DE SAÚDE. Classificação de transtornos mentais e de comportamento: CID-10. Porto Alegre: Artes Médicas, 1993.

ORTEGA, F. "O sujeito cerebral e o movimento da neurodiversidade". Mana, Rio de Janeiro, v. 14 n. 2, p. 477-509, 2008.

."Deficiência, autismo e neurodiversidade". Ciência e Saúde Coletiva, v. 14, n. 1, p. 67-77, 2009.

PORTOCARRERO, V. As Ciências da Vida: de Canguilhem a Foucault. Rio de Janeiro: Fiocruz, 2009.

RABELLO, S. Mesa Redonda: “Diagnósticos na infância: É possível ir além de uma clínica do 'déficit'?" In: IV Simpósio do CRIA - UNIFESP: A Saúde Mental na Infância e Adolescência. São Paulo, 02 de outubro de 2010. Apresentação oral. 
ROUDINESCO, E. "Georges Canguilhem: uma filosofia do heroísmo". In: Filósofos na tormenta. Trad. de André Telles. Rio de Janeiro: Jorge Zahar, 2007, p. 13-59.

RUSSO, J. et al. "Entre o corpo e a mente: a noção de indivíduo na assistência de um hospital psiquiátrico universitário". In: LEIBING, A. (org.). Tecnologias do Corpo: Uma antropologia das medicinas no Brasil. Rio de Janeiro: Nau, 2004, p. 37-56.

RUSSO, J.; VENÂNCIO, A. T. "Classificando as pessoas e suas perturbações: a revolução terminológica do DSM III". Revista Latinoamericana de Psicopatologia Fundamental, v. 9, n. 3, p. 460483, 2006.

WING, L. Anais do 5o. Congresso Autismo-Europa, Barcelona, 1996 (Tradução de Marialice de Castro Vatavuk). 